\title{
Soil sterilization and organic carbon, but not microbial inoculants, change microbial communities in replanted peach orchards
}

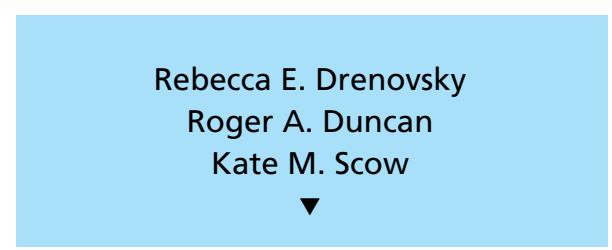

Methyl bromide is highly effective in reducing soil pathogens. Although its use was to be phased out completely in the United States by Jan. 1, 2005, due to environmental concerns, a 1-year critical-use exemption will allow tree fruit growers to use the fumigant through the end of the year. To explore possible replacements for methyl bromide, we compared the effects of pre- and postplant treatments and amendments on soil microbial communities and tree vigor in a replanted peach orchard. Both soil sterilization treatments and organic carbon amendments changed the composition of microbial communities in the soil. High microbial biomass is generally considered beneficial to agricultural soils; we found that it was usually highest in soils that received the organic carbon amendment and lowest in those with soil sterilization. However, tree vigor was highest with the sterilization treatments. The effects of a microbial inoculants/organic carbon combination on microbial communities and plant vigor were no different from simply adding organic carbon.

When old, low-yielding orchards $\checkmark$ are replaced in the San Joaquin Valley, growers must first combat nematodes and pathogens resident in the sandy soils or run the risk of reduced yields due to the replant problem or "disorder." The replant problem is caused by a complex of soil-borne nematodes and poorly characterized microbial pathogens (Radewald et al. 1987;

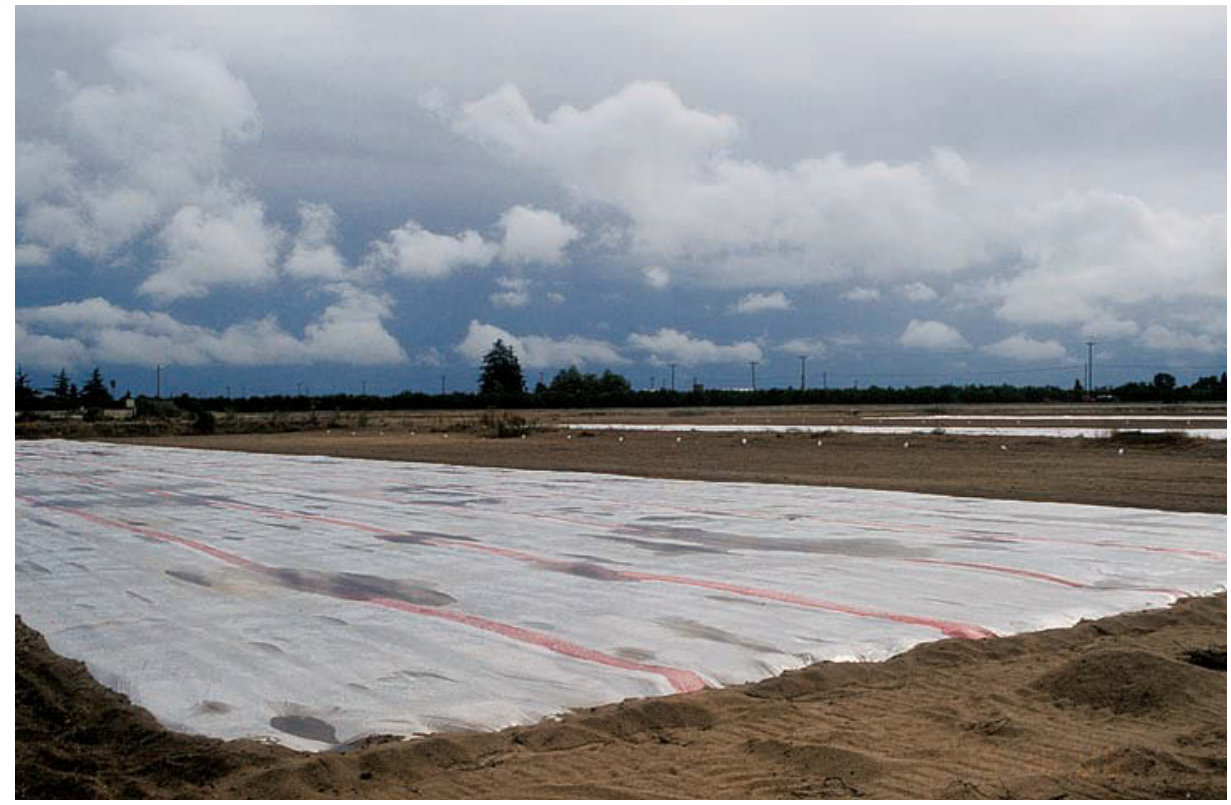

Browne et al. 2004). Several nematodes are common in these soils, including ring (Mesocriconema xenoplax), root lesion (Pratylenchus vulnus) and root knot (Meloidogyne spp.). Ring nematodes are associated with the bacterial canker complex, which can kill limbs and often entire trees in young replanted Prunus species orchards. Preplant soil fumigation with methyl bromide reduces the level of plant pathogens and can often increase tree vigor and yield even in areas without bacterial canker. However, while fumigated orchards grow more vigorously at first, they still may eventually succumb to bacterial canker. In addition, fumigation with methyl bromide reduces nonpathogenic taxa of the native soil microbial community, which can result in a reduced competitive environment for pathogens (Shiomi et al. 1999; van Elsas et al. 2002).

Furthermore, methyl bromide fumigation may contribute to the depletion of the Earth's ozone layer, and it was scheduled to be phased out completely in all "developed" nations by Jan. 1, 2005, forcing growers to find alternative soil treatments. Although alterna- tive fumigants have been studied in the greenhouse or on a small scale in the field, there have been few large-scale, commercial, field trials comparing these strategies until recently. At the same time, interest in organic and microbial amendments as possible pest-management strategies is increasing among Central Valley growers. Organic amendments - such as composted green waste and manures - provide nitrogen and other nutrients, and supply organic carbon necessary for native microbial community growth, which may improve soil quality. Microbial soil amendments are commercial preparations that include various microbial taxa, often in conjunction with fertilizer or an organic carbon-based microbial "food source." Marketers claim that their products will provide "beneficial" microorganisms and improve the health and vigor of the soil microbial community and, consequently, improve the performance of cultivated crops. However, the efficacy of these alternative products compared to, or in addition to, methyl bromide and other fumigants has not been rigorously assessed. 


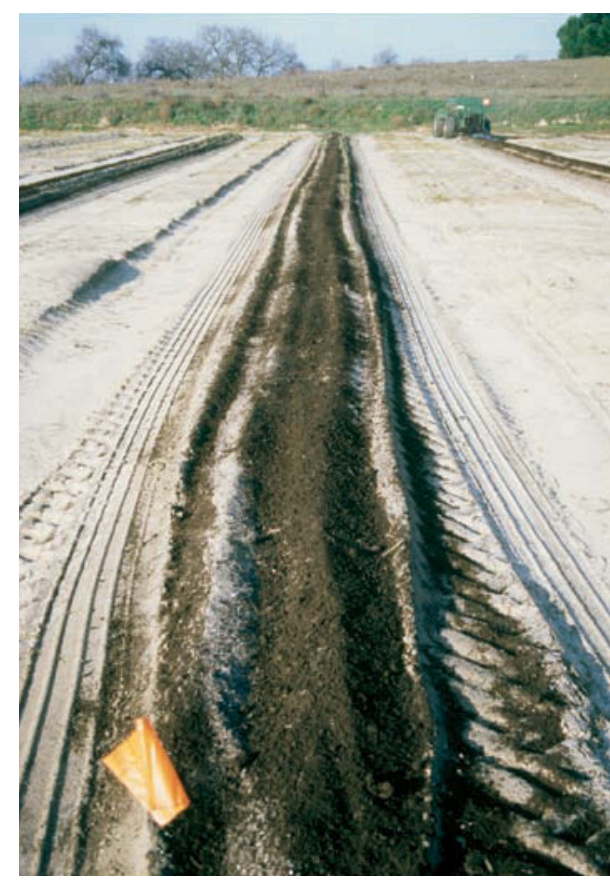

With methyl bromide in the midst of being phased out, the authors compared replacement treatments for replanted peach orchards, including: facing page, tarped methyl bromide fumigation; above, compost spread down the row prior to planting; right, tree roots dipped in microbial inoculant; and, far right, the nematicide sodium tetrathiocarbonate (Enzone) injected through the dripirrigation system after planting.

We conducted a trial in a replanted peach orchard, which compared the effects of a suite of pre- and postplant treatments on tree growth and yield as well as on soil microbial community composition. Microbial community composition was measured using phospholipid fatty acid (PLFA) analysis. Phospholipids are integral cellmembrane components, which rapidly degrade following cell death, and different types of microorganisms have different phospolipids. Since phospholipids turn over rapidly in soil, PLFA composition offers a snapshot of the living microbial community at the time of sampling. PLFA analysis also provides a quantitative biomass measurement and, since specific lipids are considered biomarkers for different groups of microorganisms (such as fungi versus bacteria, and gram-positive versus gram-negative bacteria), results can indicate the relative abundance of different microbial groups. PLFA analysis is also very sensitive to environmental perturbations and can detect shifts in microbial community composition following treatments. This method has been used in other agricul-
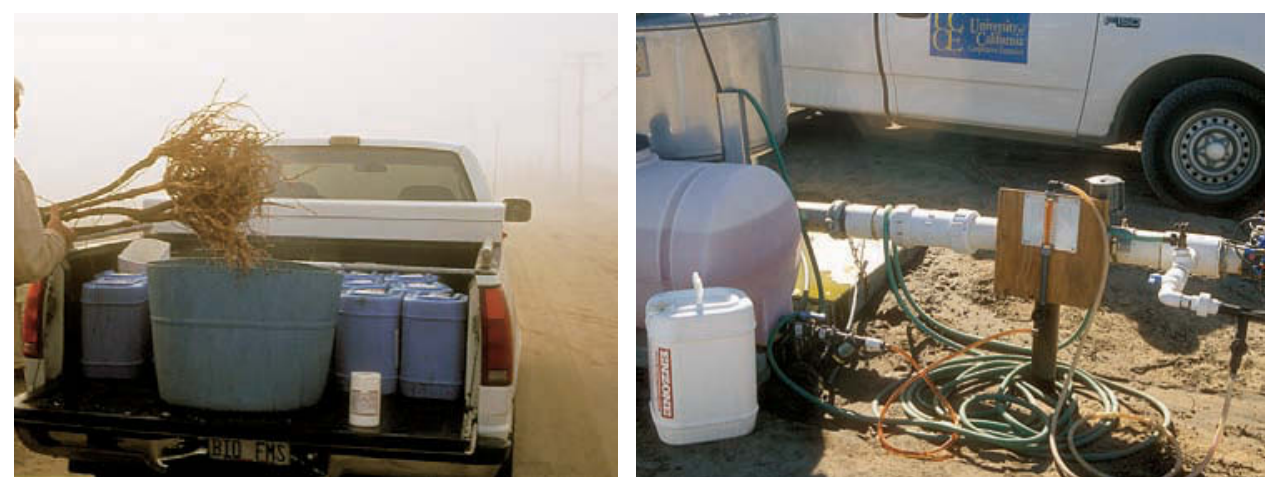

tural systems to compare management practices and crop and soil types (Bossio and Scow 1997; Calderon et al. 2001; Steenwerth et al. 2002; Yao et al. 2000).

A field study of the effects of preand postplant treatments on plant vigor and microbial community composition was initiated in fall 2000 at a former peach orchard site north of Modesto, Calif. The peach orchard suffered from bacterial canker and had been removed 2 years prior. The soil at this site is classified as a Delhi sand. Each treatment replication was 36 feet by 65 feet and consisted of two adjacent rows of 10 trees each. In total, a factorial combination of 30 pre- and postplant treatments was applied in a randomized complete block design in an area covering 6.6 acres. For this study, nine of these treatments were analyzed (table 1 ).

The preplant soil fumigants methyl bromide (98\% methyl bromide, $2 \%$ chloropicrin), metam sodium (Vapam) and 1,3-dichloropropene (Telone II) were applied in October 2000 with commercial application equipment. Composted green waste and steer manure were banded on the soil surface down some of the tree rows in fumigated and unfumigated areas before the planting of peach trees in February 2001. Compost and native soil were backfilled into the planting holes. Kelp extract, humic acid and microbial inoculants were applied at planting and periodically through the growing season in 2001 and 2002 in two of the three compost-amended treatments. Composted green waste and manure were applied again under the trees in January 2002. As a nonchemical alternative to preplant fumigants, one of the treatments included black poly- ethylene film mulch applied to the soil surface in April 2001, 2 months after the trees were planted. Black polyethylene mulch heats the soil to temperatures lethal to nematodes and soil-borne pathogens but sublethal to newly planted trees (Duncan et al. 1992). A nematicide, sodium tetrathiocarbonate (Enzone), was applied through the drip-irrigation system in October 2001 as a postplant treatment (table 1).

\section{Measuring microbial communities}

One year after soil fumigation (October 2001), the top 18 inches of soil were sampled using an Oakfield soil tube. One soil sample was collected underneath each of 10 to 12 trees in each plot. Samples were collected 2 to 3 inches from the drip emitters and then mixed together before analysis. Soil was frozen immediately after sampling and maintained at $-4^{\circ} \mathrm{F}$ until phospholipid extraction. Each sample was analyzed for microbial community size and composition using PLFA analysis. Phospholipids were extracted from 8 grams of soil dry weight (DW), fractionated, methylated and analyzed as fatty-acid methyl esters by gas chromatography (see Bossio and Scow [1998] for complete description of methods).

Correspondence analysis. The data were analyzed using correspondence analysis to determine relationships between samples and to identify which fatty acids were similar or unique among the soil samples (Steenwerth et al. 2002; CANOCO for Windows version 4.5 , Ithaca, N.Y.). Correspondence analysis transforms a data set containing many variables (in this case, amounts

\section{The use of polyethylene mulch should be investigated further as an alternative to chemical soil fumigation.}


TABLE 1. Pre- and postplant treatments, including application date and rate

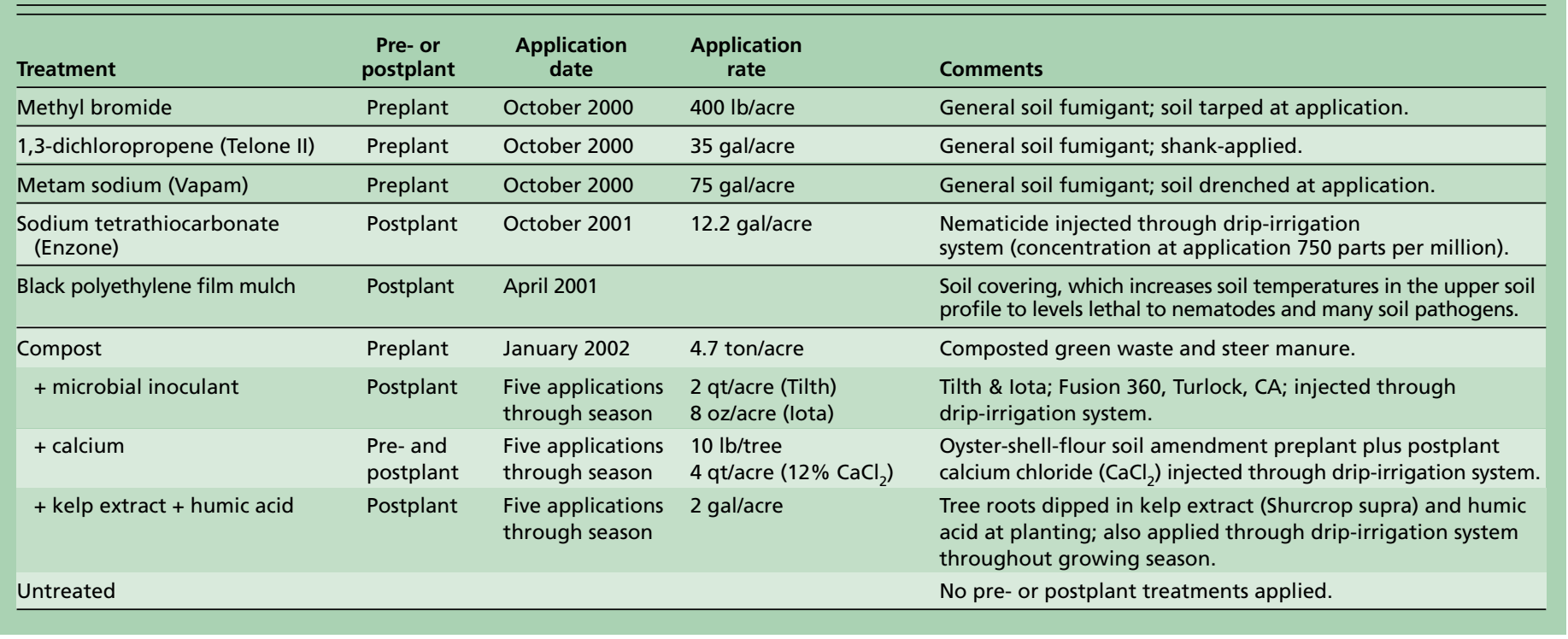

and types of fatty acids) into a smaller set of new variables, or dimensions. Each dimension is a unique combination of all the fatty acids, which explains a percentage of the total variation in the original data set. A multidimensional plot can show relationships in microbial community composition among soil samples; samples with similar microbial communities plot closer together than those with less-similar community composition.

Correspondence analysis also can identify which particular fatty acids are most important in determining the relationships among soil samples. While some of these fatty acids are biomarkers for specific groups of organisms, many fatty acids contributing to the fingerprints are common to large groups and cannot provide diagnostic information about which organisms increase or decrease with different soil treatments (Bossio and Scow 1998). A total of 34 lipids were included in our correspondence analysis. After statistical analysis, ellipsoids were drawn on the plots to indicate treatment groupings. ANOVA followed by a post-hoc Tukey's test was used to compare these ellipsoids, based on their first-axis correspondence analysis scores (SAS version 8.1, Cary, N.C.).

Cluster analysis. In addition to correspondence analysis, treatments were compared using hierarchical cluster analysis (SPSS version 11, Chicago, Ill.). To reduce sample-to-sample vari- ability due to soil heterogeneity and to ease visual interpretation of the results, replicates were averaged before analysis. In cluster analysis, treatments (or samples) are compared based on how dissimilar they are in community composition (that is, lipid composition). In our analysis, we used a measure of dissimilarity that is more strongly influenced by dominant lipids (those found in many samples) rather than rare lipids (those found in few samples). Following analysis, a dendrogram (tree) was created to visualize the results. Treatments that are less similar to one another are visualized by longer branches on the tree, whereas more-similar treatments are connected by shorter branches. As with the correspondence analysis, a total of 34 lipids were used to create the dendrogram.

Evaluating tree vigor. At the end of the first growing season (November 2001), trunk circumference was measured as an indicator of plant vigor. Trunk circumference was measured approximately 12 inches from the ground. The mass of the first dormant pruning (April 2002) was also measured. For both variables, each replicate measurement is the average of 12 trees (that is, subsamples) per block for a total of four replicates per treatment. ANOVA was used to determine if treatment significantly affected tree vigor. Post-hoc Tukey's tests were used to compare means between treatments $(\alpha=0.05)$.

\section{Effects on soil microbiology}

The total amount of PLFA is an indicator of total microbial biomass present in the samples, plus a minor amount of plant biomass. The average total PLFA varied by treatment, ranging from 17 to 35 nanomoles per gram of soil dry weight ( $\mathrm{nmol}$ $\left.\mathrm{g}^{-1} \mathrm{DW}\right)($ table 2$)$. Although not significant $(P=0.06)$, there was a trend toward higher total PLFA in soils amended with organic carbon (such as compost plus microbial inoculant, compost plus calcium, and compost plus kelp extract plus humic acid) than in nonamended soils (such as fumigated soils and untreated soils), as determined by linear contrasts following univariate ANOVA. Most soil

\begin{tabular}{|c|c|}
\hline \multicolumn{2}{|c|}{$\begin{array}{l}\text { TABLE 2. Total nanomoles PLFA* } \\
\text { in each treatment }(n=4 \text { to } 7)\end{array}$} \\
\hline \multirow[t]{2}{*}{ Treatment } & $\begin{array}{l}\text { Mean total } \\
\text { PLFAt }\end{array}$ \\
\hline & $n m o l / g^{-1} \pm S E$ \\
\hline Untreated & $26.4 \pm 2.1$ \\
\hline Methyl bromide & $19.6 \pm 2.7$ \\
\hline 1,3-dichloropropene (Telone II) & $25.3 \pm 2.5$ \\
\hline Metam sodium (Vapam) & $21.4 \pm 1.3$ \\
\hline $\begin{array}{l}\text { Sodium tetrathiocarbonate } \\
\text { (Enzone) }\end{array}$ & $26.6 \pm 2.1$ \\
\hline Polyethylene film mulch & $17.7 \pm 0.9$ \\
\hline Compost + microbial inoculant & $31.7 \pm 2.9$ \\
\hline Compost + calcium & $35.4 \pm 3.1$ \\
\hline $\begin{array}{l}\text { Compost + kelp extract } \\
+ \text { humic acid }\end{array}$ & $32.6 \pm 4.0$ \\
\hline $\begin{array}{l}\text { * Phospholipid fatty acids (nmol/g dry } \\
\text { t Although not significant, there was } \\
\text { higher total PLFA in those treatmen } \\
\text { organic carbon amendment, as dete } \\
\text { contrast following ANOVA }(P=0.06\end{array}$ & $\begin{array}{l}\text { weight soil). } \\
\text { a trend toward } \\
\text { s including an } \\
\text { rmined by linear } \\
\text {. }\end{array}$ \\
\hline
\end{tabular}


microbial communities are carbon-limited (Alden et al. 2001). Providing labile (available) organic carbon in the form of compost, extracts, organic acids and microbial biomass (from the inoculant) likely selected for those members of the microbial community that could rapidly use the carbon as an energy source and produce new biomass.

Organic carbon inputs and soil sterilization treatments also influenced microbial community composition, as detected by correspondence analysis (figs. 1A and 1B). Polyethylene filmmulched and fumigated (metam sodium, 1,3-dichloropropene and methyl bromide) soils grouped separately from the organic carbon-amended soils along the first axis, which explained $34.2 \%$ of the data variation. The untreated and sodium tetrathiocarbonate samples were grouped toward the center of the plot, between the sterilized soils and the organic carbon-amended soils.

When the first-axis correspondence analysis scores were compared using ANOVA followed by a post-hoc Tukey's test, the samples grouped into three classes (table 3). The soil sterilization samples had scores that were significantly different from all other samples $(P<0.003)$. Although the organic carbon-amended samples had significantly different scores $(P<0.01)$ from the untreated and soil sterilization samples, they were not significantly different from the sodium tetrathiocarbonate samples. Lastly, the sodium tetrathiocarbonate and untreated sample scores were not significantly different from one another $(P<0.05)$. It is less clear which environmental factors influenced the separation of the samples along axis 2 (figs. $1 \mathrm{~A}$ and $1 \mathrm{~B}$ ) - which explains $21.8 \%$ of the variation in the data - because the samples did not group by any of the treatments. Likely, this axis is influenced by factors that were not measured in this study.

In general, the soil sterilization samples were more enriched in: the straight-chain saturated fatty acids (which are common in many organisms); 10 methylated fatty acids (often considered indicative of actinomycetes, filamentous bacteria often involved in decomposing complex organic matter); and the longer-chain fatty acids (containing greater than 20 carbons, which may be indicative of protozoa or other eukaryotic organisms).

Similar enrichment in actinomycete biomarker PLFAs was observed in a microcosm study that focused on the effects of the fumigant metam sodium on microbial community composition using total soil fatty acid methyl esters (Macalady et al. 1998). In contrast, organic carbonamended treatments were more enriched in monounsaturated fatty acids, which are thought to be indicative of the presence of available carbon. The enrichment of monounsaturated fatty acids has been observed in other agricultural systems following the addition of organic carbon. For example, monounsaturated fatty acids were also enriched in rice straw incorporation in a periodically flooded California rice soil (Bossio and Scow 1998) and manure additions in a Tennessee no-till soil (Peacock et al. 2001). One of the most striking characteristics of these results is the lack of a unique fingerprint in those soils treated with microbial inoculants. Despite marketing claims suggesting that microbial inoculants enrich soil microbial communities, we did not observe this effect in our samples. Instead, inoculated soils had microbial communities very similar to uninoculated soils amended with organic carbon.

Various hypotheses can be offered as to why inoculated soils did not have unique microbial communities. First, all of the organic carbon-amended soils included compost and thus labile carbon, which may have swamped out any other treatment effects. Second, soil is a harsh environment and the microorganisms in the inoculant may not have been sufficiently competitive with the native microbial communities to significantly
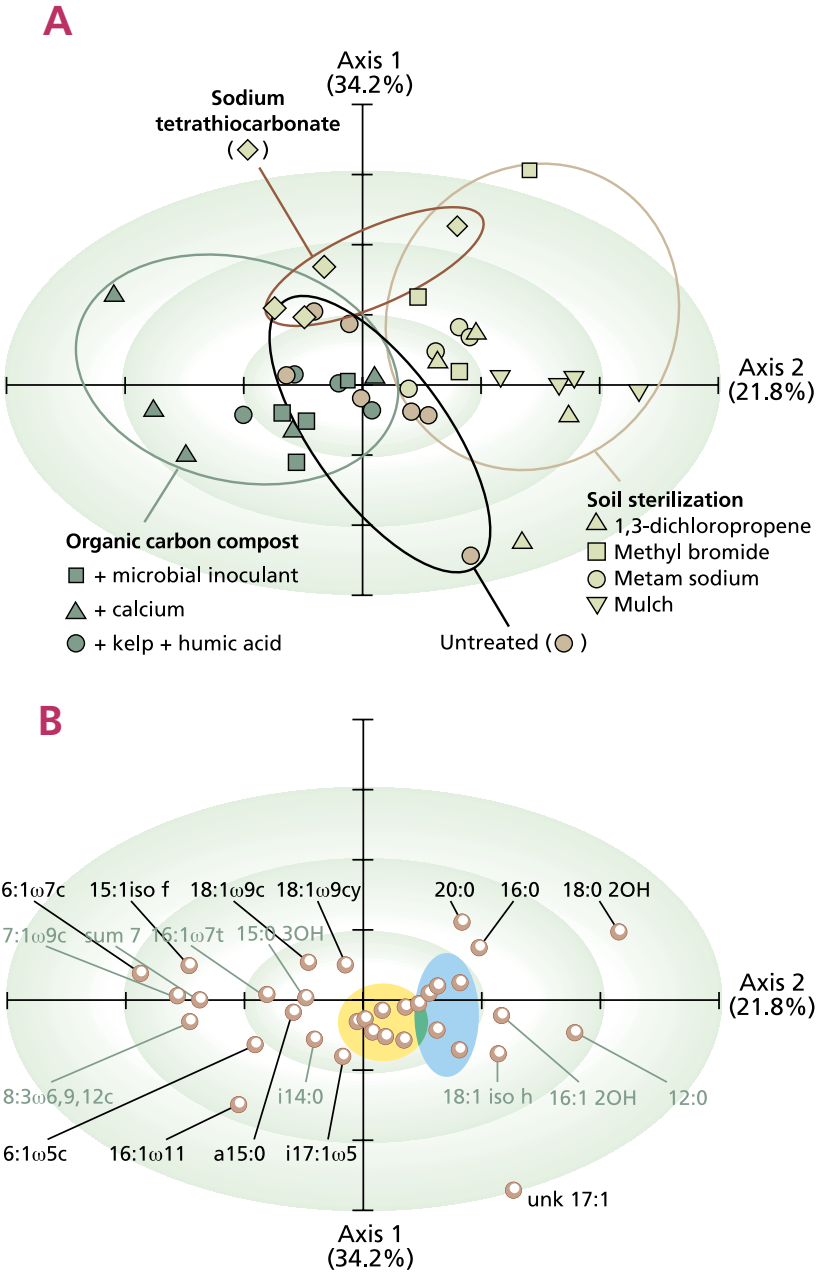

Fig. 1. Results from correspondence analysis of phospholipid fatty acid (PLFA) data. (A) In an ordination plot of the sample scores, treatments with similar microbial communities plotted closer together than treatments with less-similar microbial communities. (B) In an ordination plot of the fatty acid scores, comparison with sample plot location in fig. 1A indicates which fatty acids are enriched in specific samples. The yellow ellipsoid includes the fatty acids 15:0, i15:0, i16:0, 10Me 16:0, a17:0, i17:0, and sum 9 (a composite of the lipids); the blue ellipsoid includes the fatty acids 14:0, 17:0, 10Me 17:0, 18:0, 19:0cy, and sum 3 (a composite of four lipids).

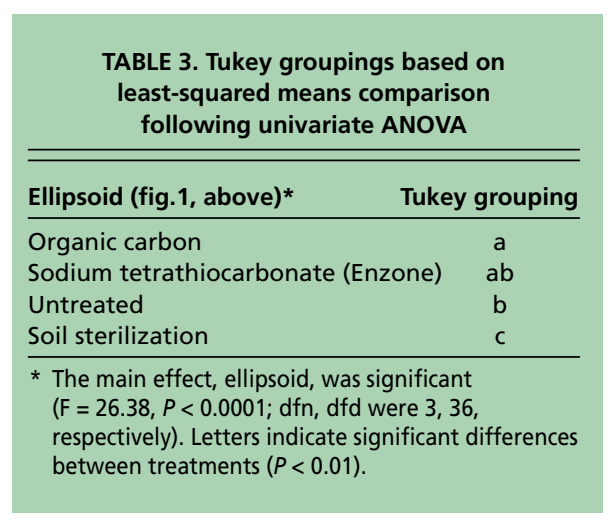




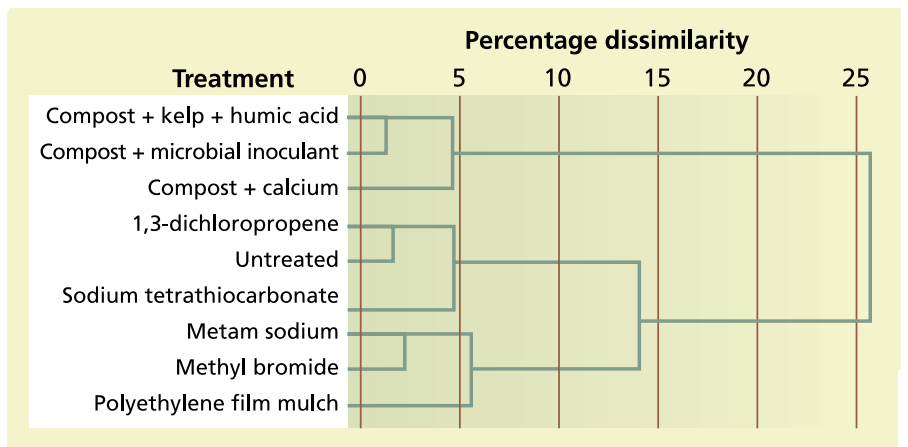

Fig. 2. Dendrogram of all treatments based on cluster analysis. Treatments are separated based on their dissimilarity, which is indicated by the top axis.

alter the microbial fingerprint. As the organisms from the inoculant died, they entered the labile carbon pool and so served as an additional organic carbon resource for the native microbial community. Finally, the diversity of the inoculant community may have been too low to have an effect on overall diversity of the soil microbial community. Commercial microbial inoculants typically include fewer than 40 taxa, or even as few as 10 taxa. In contrast, the native microbial community can include as many as 1,000 microbial taxa within a gram of soil (Torsvik et al. 1990).

However, we also found that microbial inoculants had no overall effect on microbial community composition in two other California vineyard trials (R.E. Drenovsky and K.M. Scow, unpublished data). Our current data suggests that the inoculants employed here had little effect on the soil microbial community. Rather, the presence of labile organic carbon apparently had a greater influence on the composition of the orchard soil microbial communities. With organic carbon inputs, there was a trend toward higher microbial biomass, and the microbial community composition was altered.

Similar to the results from the correspondence analysis, the primary factor separating treatments in the cluster analysis was the addition of organic carbon (fig. 2). The three organic carbon treatments were more than $95 \%$ similar in lipid composition to one another, and they grouped separately from all other treatments, from which they were approximately $25 \%$ dissimilar in lipid composition. The second branch of the tree was then split into two further clusters, one including sodium tetrathiocarbon- ate, 1,3-dichloropropene and untreated samples, and the other including methyl bromide, metam sodium and filmmulched samples. These results provide further support for our supposition that microbial inoculants had little effect on microbial community composition. Likewise, it suggests that polyethylene mulch produces a similar effect on microbial communities as chemical fumigants. From a microbial perspective, the use of polyethylene mulch should be investigated further as an alternative to chemical soil fumigation.

\section{Tree vigor and soil nutrients}

It is important to consider the soil microbial community data within the context of the entire soil food web. Although organic carbon amendments increased microbial biomass and influenced microbial community composition, they had no effect on first-year tree growth and vigor, as assessed by trunk circumference and first-year pruning masses. In contrast, trees growing in areas fumigated with methyl bromide had greater trunk diameters than trees growing in areas treated with the organic carbon amendments (compost plus kelp extract plus humic acid, compost plus microbial inoculants, and compost plus foliar and drip-applied calcium) or sodium tetrathiocarbonate, and had trunk diameters 1.4-fold greater than the control trees (fig. 3A).

However, trees growing in areas fumigated with metam sodium or 1,3dichloropropene, or treated with the black polyethylene film mulch, had tree diameters that were not significantly different from either group after 1 year of growth. In addition, trees growing in areas fumigated with methyl bromide

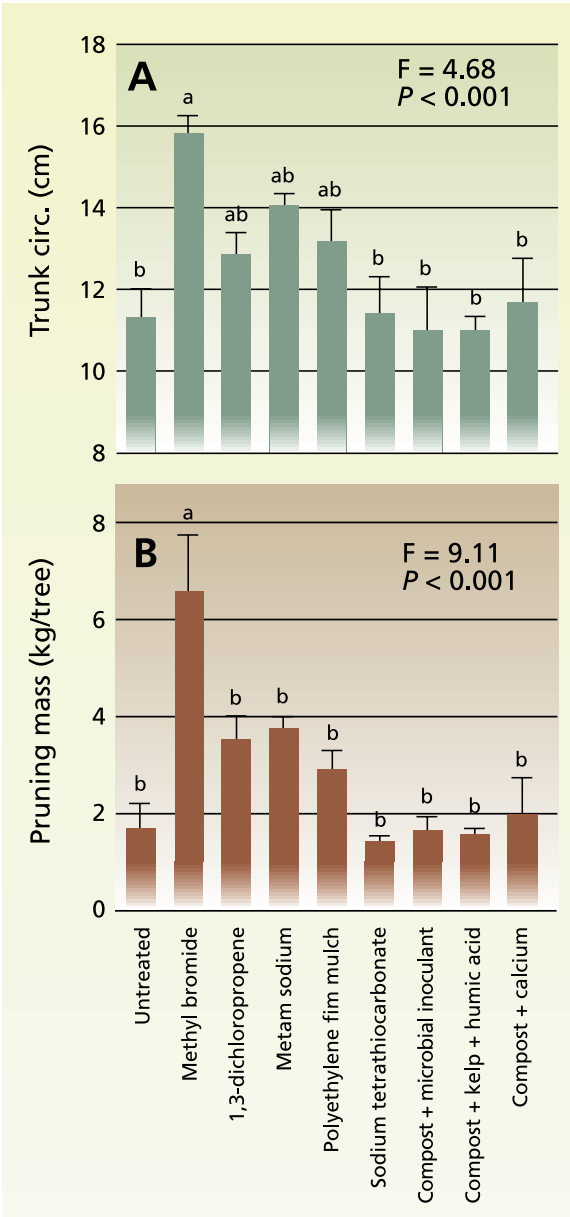

Fig. 3. (A) Average trunk circumference (centimeters) and (B) first year's pruning mass in each treatment $(n=4$, bars are means \pm $\mathrm{SE}$ ). Letters indicate a significant difference between treatments following post-ANOVA Tukey's test ( $\alpha=0.05$; for ANOVA model dfn $=3, \mathrm{dfd}=35$ ).

had the highest pruning masses (3.9-fold greater than controls), with all other treatments having significantly lower pruning masses (fig. 3B). Tree vigor may have been related, in part, to differences in soil nutrient availability due to indirect treatment effects. For example, soil sterilization treatments may have contributed to soil nutrient pools by killing soil microorganisms.

In contrast, higher microbial biomass in the organic carbon treatments may have led to greater immobilization of soil nutrients. Additionally, at our site, soil sterilization significantly lowered nematode numbers (R.A. Duncan, unpublished data), possibly promoting greater tree growth and vigor in these treat- 


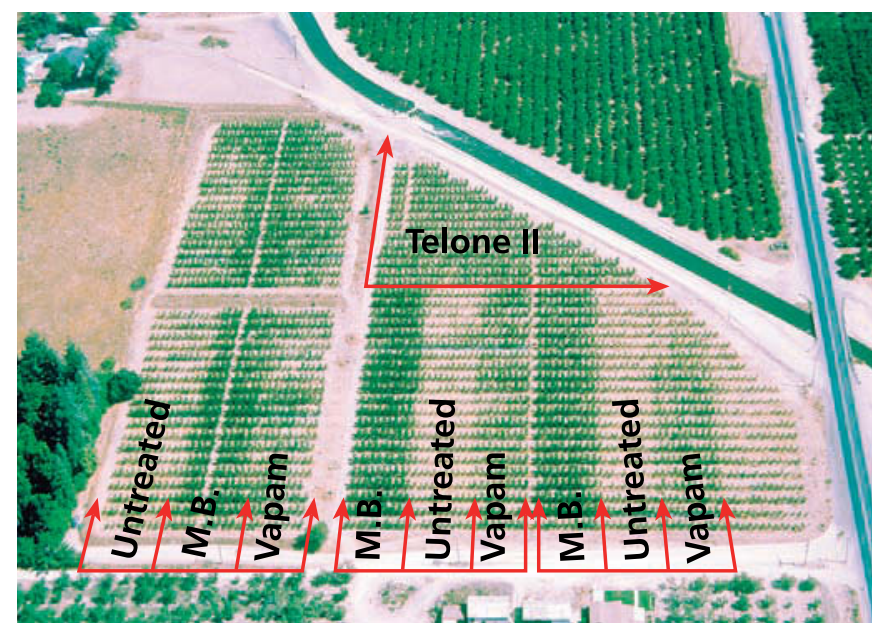

Peach trees in the methyl bromide (M.B.), 1,3-dichloropropene (Telone II) and metam sodium (Vapam) plots grew more vigorously (shown, darker rows), as opposed to less-leafy untreated control plots.

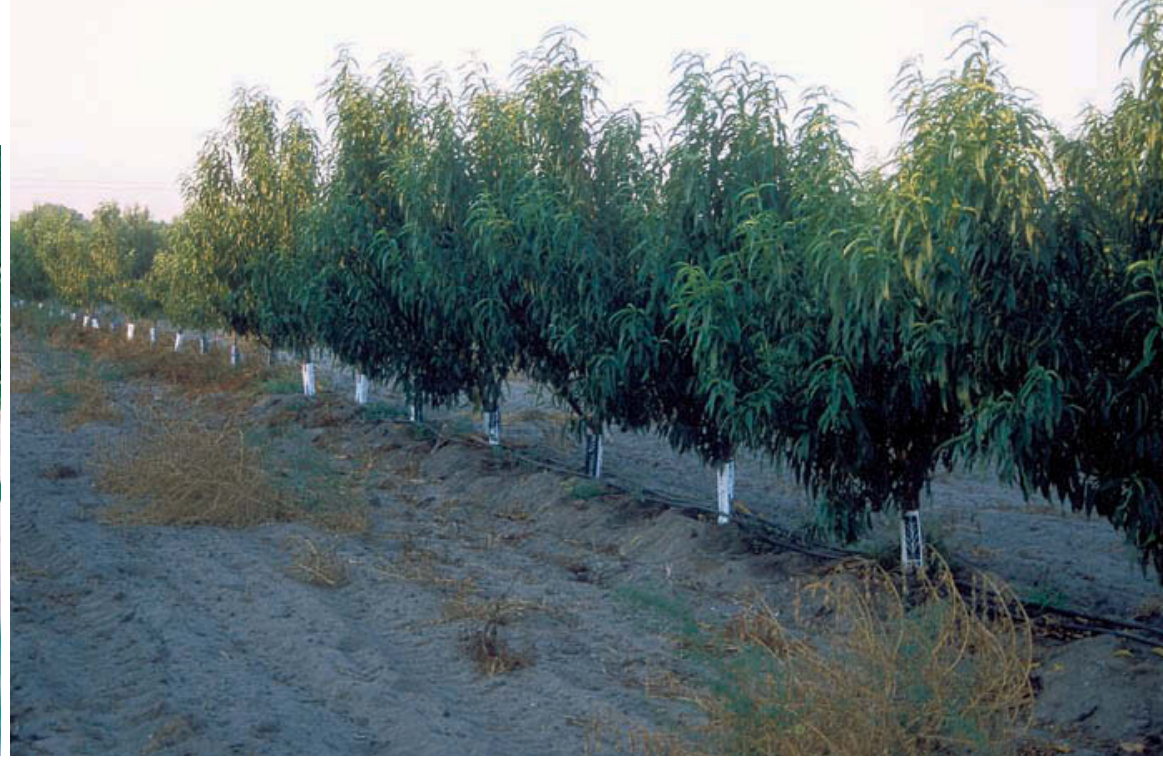

In general, the fumigation and polyethylene film mulch treatments tended to suppress microbial biomass in the soil but improve tree vigor. Above, methyl bromide-fumigated trees are in the foreground, with unfumigated trees behind. ments. Finally, reduced numbers of other soil-borne pathogens in the soil sterilization treatments may have increased tree growth and vigor. Research in apple orchards (Mazzola 1998) and vineyards (Westphal et al. 2002) suggests that specific fungal species, such as Pythium spp., may play a role in replant disease.

\section{Microbial community composition}

Overall, pre- and postplant treatments had opposing effects on microbial communities and peach tree vigor. Although treatments including compost tended to increase microbial biomass and influence microbial community composition, they had no measurable effect on plant vigor. In contrast, fumigants and the black polyethylene film mulch tended to suppress microbial biomass but increase tree vigor. It is possible that there could be continued reductions in microbial biomass in future growing seasons, which could have negative impacts on the orchard such as lower nutrient pools, but this hypothesis requires further research. Lastly, microbial-based amendments (that is, inoculants) in conjunction with organic carbon amendment had the same effect on microbial biomass, community composition and plant vigor as did adding organic carbon amendments alone. This study also suggests that commercial soil inoculants should not be substituted for preplant fumigation, and may have limited value in a commercial orchard setting.
R.E. Drenovsky is Postdoctoral Researcher, and K.M. Scow is Professor, Department of Land, Air and Water Resources, UC Davis; and R.A. Duncan is Farm Advisor, UC Cooperative Extension, Stanislaus County. The authors thank Kevin Feris for manuscript review, and Kim Chuong, Levina Loveless, Anita Setty and Angela Maroney for sample preparation and analysis. A special thank you is extended to Norman Kline, grower, for participating in the trial. A grant from the California Cling Peach Board made this work possible.

\section{References}

Alden L, Demoling F, Bååth E. 2001. Rapid method of determining factors limiting bacterial growth in soil. Appl Environ Microbiol 67:1830-8.

Bossio DA, Scow KM. 1997. Management changes in rice production alter microbial community. Cal Ag 51(6):33-40.

Bossio DA, Scow KM. 1998. Impacts of carbon and flooding on soil microbial communities: Phospholipids fatty acid profiles and substrate utilization patterns. Microbiol Ecol 35:265-78.

Browne GT, Kluepfel DA, Connell J, et al. 2004. Biology and management of replant disorder and lethal phytophthora canker. 32nd Almond Industry Conference Proceedings. p 138-46. www.almondboard.com.

Calderon FJ, Jackson LE, Scow KM, Rolston DE. 2001. Short-term dynamics of nitrogen, microbial activity, and phospholipid fatty acids after tillage. Soil Sci Soc Am J 65:118-26.

Duncan RA, Stapleton JJ, McKenry MV. 1992. Establishment of orchards with black polyethylene film mulching: Effect on nematode and fungal pathogens, water conservation, and tree growth. J Nematol 24(4S):681-7.

Macalady JL, Fuller ME, Scow KM. 1998. Effects of metam sodium fumigation on soil microbial activity and community structure. J Environ Qual 27:54-63.

Mazzola M. 1998. Elucidation of the microbial complex having a causal role in the development of apple replant disease in Washington. Phytopathol 88:930-8.

Peacock $A D$, Mullen MD, Ringelberg $D B$, et al. 2001. Soil microbial community responses to dairy manure or ammonium nitrate applications. Soil Biol Biochem 33:1011-9.

Radewald JD, McKenry MV, Roberts PA, Westerdahl BB. 1987. The importance of soil fumigation for nematode control. Cal $\mathrm{Ag}$ 41(11,12):16-7.

Shiomi Y, Nishiyama M, Onizuka T, Marumoto T. 1999. Comparison of bacterial community structures in the rhizoplane of tomato plants grown in soils suppressive and conducive towards bacterial wilt. Appl Environ Microbiol 65:3996-4001.

Steenwerth $\mathrm{KL}$, Jackson LE, Calderon FJ, et al. 2002. Soil microbial community composition and land use history in cultivated and grassland ecosystems of coastal California. Soil Biol Biochem 34:1599-611.

Torsvik V, Salte K, Sørheim R, Goksøyr J. 1990. Comparison of phenotypic diversity and DNA heterogeneity in a population of soil bacteria. Appl Environ Microbiol 56:776-81.

Van Elsas JD, Garbeva P, Salles J. 2002. Effects of agronomical measures on the microbial diversity of soils as related to the suppression of soil-borne plant pathogens. Biodegradation 13:29-40.

Westphal A, Browne GT, Schneider S. 2002. Evidence for biological nature of the grape replant problem in California. Plant Soil 242:197-203.

Yao H, He Z, Wilson MJ, Campbell CD. 2000. Microbial biomass and community structure in a sequence of soils with increasing fertility and changing land use. Microbiol Ecol 40:223-37. 